\title{
Shortcomings of the short Synacthen test; a near miss case of Addison's disease
}

A Sharma, P Avari, K Muralidhara

Department of Endocrinology, Northwick Park Hospital, London North West Healthcare NHS Trust, UK

\section{INTRODUCTION}

- The 'short Synacthen test' first described in 1965, is widely used to confirm a clinical diagnosis of Addison's disease.

- Whilst it is mostly accepted that a normal response excludes the diagnosis of Addison's disease, we present a case of a middleaged lady with suspicious clinical features and an initial false negative short synacthen test (SST), which resulted in a delayed diagnosis of Addison's disease.

\section{CASE HISTORY}

- A 62-year Indian lady presented to A\&E with a 4 to 6 month history of generalised malaise, weakness, dizziness, vomiting and weight loss.

- Past medical history included type2 diabetes, previous left parathyroidectomy for primary hyperparathyroidism and Bthalassaemia trait.

- On examination, there was evidence of a pleural effusion with raised inflammatory markers. Buccal pigmentation was noted.

- Concerns were raised regarding adrenal insufficiency due to her clinical history and presentation.

- She received $200 \mathrm{mg}$ intravenous hydrocortisone in A\&E followed by broad spectrum antibiotics.

- Initial short synacthen test performed showed good response, it was only later due to high clinical suspicion when the test was repeated that a flat response was observed.

\section{INVESTIGATIONS}

- Admission bloods: $\mathrm{Hb}$ 106g/L, Na $129 \mathrm{mmol} / \mathrm{l} ; \mathrm{K} 5.6 \mathrm{mmol} / \mathrm{l}$; $\mathrm{Hb} 106 \mathrm{~g} / \mathrm{L}$, eGFR $76 \mathrm{~mL} / \mathrm{min} / 1.73 \mathrm{~m}^{2}$, TSH $4.79 \mathrm{mIU} / \mathrm{L}$

- Inflammatory markers: raised

- Chest X-Ray: small left pleural effusion, not amenable to pleural tap or drainage.

- Initial SST approximately 15hours post hydrocortisone dose: good response (Table 1 ).

- A few days later, SST was repeated showing flat response (Table 1).

- CT chest showed a loculated left-sided pleural effusion, as well as bulky adrenal glands suggestive of adrenal hyperplasia.

- Adrenal antibodies, remaining pituitary screen, autoimmune and viral screens: negative.

- TB excluded.

\section{OUTCOMES}
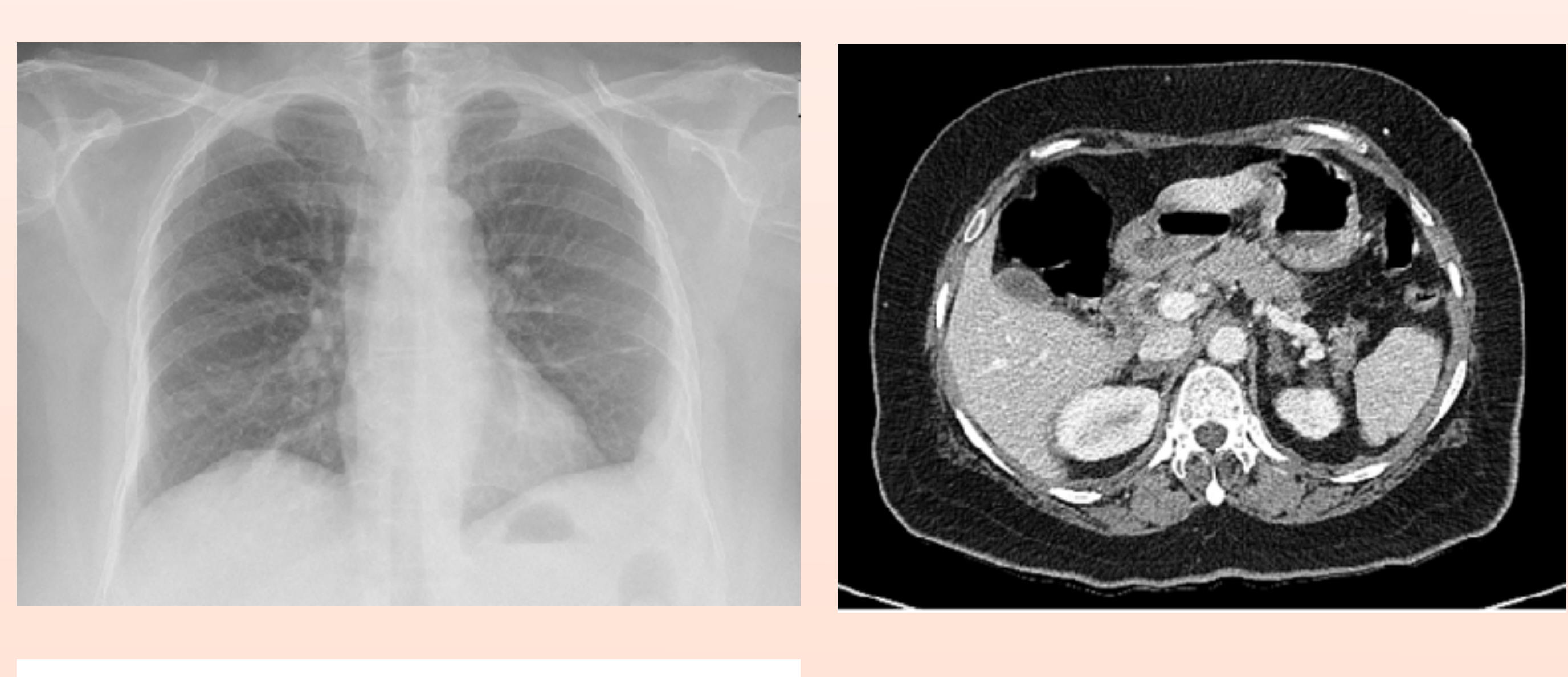

Image 1: Left: Chest showing small left pleural effusion.
Right: CT abdomen showing normal

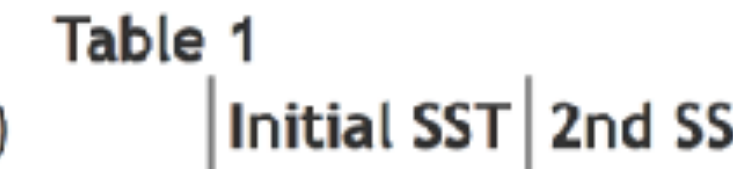

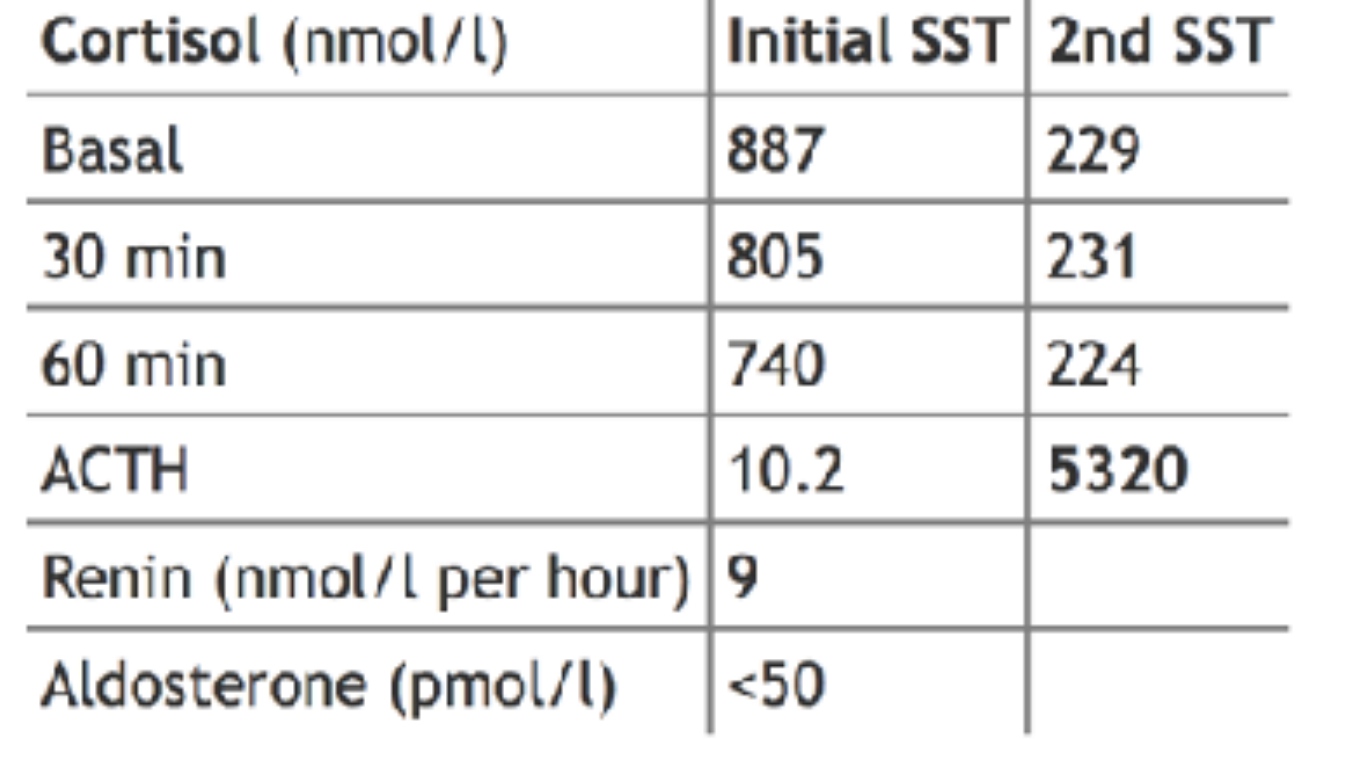
Table 1: Initial SST approximately 15hours post
hydrocortisone dose: good response (Table 1). A few days
later, SST was repeated showing flat response

- Following her diagnosis of Addison's, she was initiated on hydrocortisone and her clinical symptoms improved significantly.

- She is now followed up routinely in our endocrinology clinic and is clinically well on prednisolone $4 \mathrm{mg} /$ day.

\section{DISCUSSION}

- Whilst the SST remains the standard screening test for hypoadrenalism, this case demonstrates the importance of ensuring results are interpreted in context of the clinical suspicion.

- The initial false negative SST in our patient may be due to the initial hydrocortisone dose received, although this was 15 hours prior.

- The biological half-life of hydrocortisone is approximately 100 mins, however this may be increased in context of stress, acute illness, certain diseases, and concomitant drugs (e.g. hepatic microsomal inhibitors of cytochrome P-450).

- Where clinical suspicion remains high, the test should be repeated, ideally in a non-acute setting to prevent delay of diagnosis. 